\title{
EL CONTROL DE CONSTITUCIONALIDAD DE LOS DECRETOS CON FUERZA DE LEY*
}

CONSTITUTIONAL REVIEW OF DELEGATED LEGISLATION

LE CONTRÔLE DE LA CONSTITUTIONNALITÉ DU DÉCRET

AVEC FORCE DE LOI

Miriam Henríquez Viñas ${ }^{* *}$

\begin{abstract}
RESUMEN
El presente trabajo versa sobre la competencia del Tribunal Constitucional para ejercer el control de constitucionalidad de los decretos con fuerza de ley. Particularmente, analiza si las Cámaras o una cuarta parte de sus miembros puede recurrir al Tribunal Constitucional para impugnar el decreto con fuerza de ley vigente cuando excede o contraviene la ley delegatoria y si este supuesto implica un vicio de legalidad o de constitucionalidad.

PALABRAS CLAVE: Decreto con fuerza de ley - Ley delegatoria - Control de constitucionalidad - Tribunal Constitucional
\end{abstract}

ABSTRACT

This work focuses on the competence of the Constitutional Court to exercise judicial review of delegated legislation. Particularly analyzes whether the Chambers of Congress, or a quarter of its members, may request the Constitutional Court to challenge the delegated legislation when it exceeds or contravenes the enabling act and if this assumption implies an error of legality or constitutionality.

KEY WORDS: Decree with force of law - Law delegatoria - Control of constitutionality Constitutional Court

RÉSUMÉ

Cet article analyse e pouvoir de contrôle de la Cour constitutionnelle à l'égard des décrets avec force de loi. Notamment, on étudie si la chambre de députés ou le Sénat, ou un quart de ses membres, peut agir devant la Cour constitutionnelle pour répudier le décret avec la force de la loi, si l'on considère qu'il dépasse ou est contradictoire avec la loi déléguée et si cette hypothèse suppose un défaut de légalité ou constitutionnalité.

MOTS CLÉS: Les décrets avec force de loi-Loi déléguée - Control de constitutionnalité-Cour Constitutionnelle

\footnotetext{
* Artículo recibido el 30 de septiembre de 2013 y aceptado para su publicación el 15 de noviembre de 2013.

** Abogada de la Universidad Nacional del Comahue, Argentina. Magíster en Derecho Público con mención en Derecho Constitucional por la Pontificia Universidad Católica de Chile. Doctor en Ciencias Jurídicas por la Universidad de Santiago de Compostela, España. Profesora Derecho Constitucional Universidad Alberto Hurtado. Correo electrónico: mhenriqu@uahurtado.cl.
} 


\section{INTRODUCCIÓN}

El objetivo del presente trabajo es plantear ciertas cuestiones que permitan precisar el alcance de la competencia del Tribunal Constitucional en el control de constitucionalidad de los decretos con fuerza de ley, asunto escasamente analizado en la doctrina nacional. Más precisamente, analizaré si las Cámaras o una cuarta parte de sus miembros puede recurrir al órgano de Justicia Constitucional para impugnar el decreto con fuerza de ley vigente "cuando exceda o contravenga la ley delegatoria”.

Para la consecución del objetivo planteado, seguiré el siguiente plan de análisis. En primer término, buscaré dilucidar si se trata de un vicio de legalidad o de constitucionalidad. Luego, intentaré establecer cuál es la relación del decreto con fuerza de ley con su ley delegatoria. Finalmente, concluiré si procede o no el control de constitucionalidad por el Tribunal Constitucional cuando el decreto con fuerza de ley excede o contraviene la ley delegatoria.

\section{1. ¿VICIO DE LEGALIDAD O CONSTITUCIONALIDAD?}

Parte de la doctrina ha sostenido que cuando el decreto con fuerza de ley excede o contraviene la ley delegatoria: a) incurre en un vicio de legalidad, toda vez que se produce una discordancia entre el decreto con fuerza de ley y su ley delegatoria; b) no importa una cuestión de constitucionalidad; c) el Tribunal Constitucional carece de competencia para conocer de esta cuestión; d) sólo la Contraloría General de la República tendría la competencia para resolver este conflicto.

En tal sentido, por ejemplo, Humberto Nogueira distingue entre los vicios de legalidad y los vicios de constitucionalidad que responden a la idea de ajustarse a la ley habilitante o a la Constitución respectivamente. Asimismo agrega que cuando la ilegalidad surge antes de la entrada en vigencia del decreto con fuerza de ley, el control le corresponde a la Contraloría General de la República al conocer del acto a través de la toma de razón. Por último, expresa que es posible sostener que las normas de un decreto con fuerza de ley que exceden las facultades delegadas expresamente por la ley habilitante no son más que simples decretos ilegales que pueden ser modificados o derogados por otros decretos ${ }^{1}$.

En la misma lógica, Hernán Molina explica que el precepto del artículo 93 de la Constitución (ex artículo 82), limita expresamente el requerimiento del Presidente de la República al caso de la representación por inconstitucionalidad de un decreto con fuerza de ley, quedando impedido de accionar en el caso de representación por ilegalidad o simple antijuridicidad. Al igual que Nogueira Alcalá, explica que un decreto con fuerza de ley que excedió o contravino la ley delegatoria es una

${ }^{1}$ Nogueira Alcalá, Humberto (2001). "La delegación de facultades legislativas en el ordenamiento jurídico chileno”. Revista Ius et Praxis, Año 7, No 2, p. 79. 
apariencia de decreto con fuerza de ley, pero en realidad sólo existe un decreto supremo con la fuerza normativa de la potestad reglamentaria ${ }^{2}$.

Por su parte, Francisco Zúniga expone que queda excluido del control de constitucionalidad el juicio de legalidad del decreto con fuerza de ley que concierne a la ley habilitante, lo que es de competencia de la Contraloría General de la República ${ }^{3}$.

Agregan estos autores, que los decretos con fuerza de ley que exceden o contravienen la ley delegatoria son simples decretos ilegales con la misma fuerza y jerarquía que una norma de la potestad reglamentaria. Cabe señalar, respecto de esta última afirmación, que la misma parece tener su origen en el Derecho Constitucional español, que ha concebido, no sin discusión, que la legislación delegada es norma con rango reglamentario si se constata en ella exceso respecto de la ley delegante ${ }^{4}$. Es decir, en el Derecho español, la contravención a la ley delegatoria no significa invalidez automática de la norma, sino su degradación a simple norma reglamentaria, lo que apareja como consecuencia que cualquier juez puede inaplicar los decretos ilegales. En esta parte cabe preguntarse si tales razonamientos pueden argumentarse en nuestro sistema de Fuentes del Derecho.

Por otro lado, parte de la doctrina sostiene lo contrario, es decir: a) el decreto con fuerza de ley que excede o contraviene la ley delegatoria no es ilegal, sino que es inconstitucional, en el entendido que vulnera indirectamente la Constitución; b) el Tribunal Constitucional puede ejercer el control de constitucionalidad cuando el decreto con fuerza de ley es contrario a la Constitución como cuando excede o contraviene la ley delegatoria.

De esta forma, Ribera Neumann, quien con motivo del control de constitucionalidad por el Tribunal Constitucional opinó: "El Tribunal Constitucional ha expresado que es competente para conocer de las cuestiones de constitucionalidad que le formule el Presidente de la República, entendiendo comprendidas dentro de este concepto tanto cuando un decreto con fuerza de ley excede o contraviene la ley delegatoria, como cuando viola las disposiciones constitucionales. De este fundamento es posible argumentar que el Tribunal Constitucional es competente para declarar la inconstitucionalidad cuando la violación de las normas constitucionales se produce directamente como cuando ello es producto de la infracción de un orden jurídico que es autorizado por el constituyente y permite su existencia,

${ }^{2}$ Molina Guaita, Hernán (2001). "Los decretos con fuerza de ley en la Constitución”. Revista de Derecho Universidad Católica de Valparaíso, XXII, pp. 430 y 431.

3 Zúñiga Urbina, Francisco (2002). Elementos de Jurisdicción Constitucional. T. II, Santiago: Ediciones Universidad Central, p. 89.

${ }^{4} \mathrm{La}$ referida doctrina parece haber seguido en esta parte la doctrina conocida como ultra vires del Profesor García de Enterría. Esta tesis tuvo por objeto evitar que la legislación delegada gozara de le exención de control jurisdiccional. Ver García de EnterRía, Eduardo (1998). Legislación delegada, potestad reglamentaria y control judicial. Madrid: Editorial Civitas. 
delegación realizada en el marco de lo establecido en la Constitución (inconstitucionalidad indirecta)" 5 .

Las visiones contrapuestas, recién resumidas, permiten plantear que para resolver adecuadamente este asunto corresponde aclarar la especial relación que tiene el decreto con fuerza de ley con su ley delegatoria.

\section{LA RELACión ENTRE EL DECRETO CON FUERZA DE LEY \\ Y LA LEY DELEGATORIA}

La relación entre la ley delegatoria y el decreto con fuerza de ley es una relación particular. La importancia de identificarla y desentrañarla se encuentra íntimamente vinculada con el control de constitucionalidad del decreto con fuerza de ley. La doctrina, especialmente comparada, ha explicado la relación desde distintos argumentos.

Para algunos la ley delegatoria es la norma interpuesta, es decir una norma que sirve de parámetro en la declaración de inconstitucionalidad. Esto, por cuanto consideran que existen normas inconstitucionales por contraste no directamente con la Constitución, sino con dichas normas interpuestas, dado que la propia Constitución las sitúa en una posición superior relativa.

Para otros, la relación entre las dos normas podría construirse desde el principio de la competencia, dado que si la legislación delegada excede el ámbito fijado por la ley delegatoria estaría ejerciendo competencias legislativas que no le son propias $^{6}$.

Finalmente, hay quienes sostienen que entre la ley delegatoria y la legislación delegada existe una relación de jerarquía lógica o material a la que la Constitución atribuye trascendencia jurídica ${ }^{7}$, es decir, el decreto con fuerza de ley está subordinado a "su ley delegante" y no a la ley en general con quien comparte su jerarquía.

Claramente es necesario prestar atención a los efectos que se derivan de estas posturas, puesto que a partir de ellas se llega a soluciones distintas de la cuestión. Desde la perspectiva de la ley delegatoria, como norma interpuesta, la no concordancia del decreto con fuerza de ley con aquella implica una inconstitucionalidad.

\footnotetext{
${ }^{5}$ Ribera Neumann, Teodoro (2004). "El control de constitucionalidad de los decretos con fuerza de ley por el Tribunal Constitucional". Revista de Derecho Público, No 66, p. 143. En un sentido coincidente Henríquez Viñas, Miriam (2010). "El control de constitucionalidad de los decretos con fuerza de ley en la Ley Orgánica del Tribunal Constitucional”. En: Temas de Derecho Procesal Constitucional. Reflexiones jurídicas sobre competencias del Tribunal Constitucional y la nueva LOC del Tribunal Constitucional, NogUeIRA Alcalá, Humberto (Coord.), Santiago: Librotecnia, p. 151.

${ }^{6}$ Gutiérrez Gutiérrez, Ignacio (1995). Los controles de la legislación delegada. Madrid: Centro de Estudios Constitucionales, pp. 152-154.

${ }^{7}$ En este sentido concluye Nogueira Alcalá, quien reconoce una mayor jerarquía material de la ley delegante que se deduce de la existencia de controles administrativos y jurisdiccionales sobre la adecuación del decreto con fuerza de ley a las normas delegantes o habilitantes. Nogueira Alcalá (2001), p. 79.
} 
Igualmente desde el criterio de competencia. Sin embargo, si se sigue el criterio de la relación de jerarquía lógica o material el decreto con fuerza de ley que exceda o contravenga la ley delegatoria es ilegal.

Así, la ley delegatoria es una ley de carácter especial, en el sentido de que se dicta sólo para atribuir una competencia al Presidente de la República, por tanto no regula esencialmente materia propia de ley, sino que faculta al Presidente para que pueda hacerlo, no es abstracta, ni general, ni tiene vocación de permanencia puesto que agota su objetivo con la dictación del decreto con fuerza de ley ${ }^{8}$. De esta forma, la ley delegatoria proporciona la "medida" para comprobar si el decreto con fuerza de ley ha vulnerado la Constitución, pero eso no significa que en la jerarquía de las fuentes sea superior al decreto con fuerza de ley. En consecuencia, toda violación a la ley delegatoria se resuelve en una violación a la Constitución.

\section{Control de Constitucionalidad de los decretos}

\section{CON FUERZA DE LEY}

La Constitución fija controles para la legislación delegada, esto con miras a impedir que pueda producirse una usurpación de poderes del Presidente de la República en las funciones del legislador o que el legislador vacíe su competencia a favor del Presidente de la República. De esta forma, quedan sometidos tanto la ley delegatoria como el decreto con fuerza de ley al control de constitucionalidad.

La ley delegatoria, como cualquier ley ordinaria queda sujeta al control de constitucionalidad por el Tribunal Constitucional. La ley delegatoria puede ser inconstitucional por vicios de fondo o forma. Constituye un ejemplo de vicio de fondo que la ley delegatoria delegue la atribución al Presidente de la República y a sus Ministros de Estado, considerando que la delegación sólo es al Presidente de la República. Constituye un ejemplo de vicio de forma que la ley delegatoria no haya sido aprobada por la mayoría simple de los diputados y senadores presentes.

\subsection{Por la Contraloría General de la República}

Con respecto al control de constitucionalidad del decreto con fuerza de ley, la Constitución dispone que tanto la Contraloría General de la República como el Tribunal Constitucional ejerzan control respecto de aquél.

El control que ejerce la Contraloría es un control previo y obligatorio, de conformidad con el artículo 99.

El artículo 99 señala: "Corresponderá, asimismo, al Contralor General de la República tomar razón de los decretos con fuerza de ley, debiendo representarlos cuando ellos excedan o contravengan la ley delegatoria o sean contrarios a la Constitución. Si la representación tuviere lugar con respecto a un decreto con fuerza de ley, a un decreto promulgatorio de

${ }^{8}$ Henríquez Viñas (2010), p. 151. 
una ley o de una reforma constitucional por apartarse del texto aprobado, o a un decreto o resolución por ser contrario a la Constitución, el Presidente de la República no tendrá la facultad de insistir, y en caso de no conformarse con la representación de la Contraloría deberá remitir los antecedentes al Tribunal Constitucional dentro del plazo de diez días, a fin de que éste resuelva la controversia".

De esta forma, el Contralor General de la República ejerce un control sobre la adecuación del decreto con fuerza de ley a la ley delegatoria y a la Constitución. El Contralor deberá tomar razón si estima que el decreto con fuerza de ley es conforme a la ley delegatoria y a la Constitución, pero deberá representarlo o rechazarlo cuando considere lo contrario.

Constituyen ejemplos de decretos con fuerza de ley contrarios a la ley delegatoria: a) si excedió la ley delegatoria y se dictó sobre materias que la ley no delegó, pero dentro de las materias de ley no vedadas por la Constitución en el artículo 64; b) si excedió la ley delegatoria y se dictó en un plazo superior al fijado por la ley delegatoria pero inferior a un año; c) si contravino la ley delegatoria y se dictó sin tomar en cuenta las limitaciones, restricciones o formalidades fijadas por aquélla. Son ejemplos de decretos con fuerza de ley contrarios a la Constitución: a) si se dictó en ausencia de ley delegatoria; b) si se dictó regulando las materias que la Constitución ha vedado; c) si se dictó en un plazo superior a un año; d) si lo dictó una autoridad administrativa distinta del Presidente de la República9?.

Si la Contraloría General de la República representa el decreto con fuerza de ley, por cualquiera de las causales previstas, el Presidente de la República no puede insistir, pero puede adoptar alguna de las siguientes actitudes: a) conformarse con la representación, b) desechar el decreto con fuerza de ley, c) modificar el decreto con fuerza de ley, d) recurrir al Tribunal Constitucional en el plazo de 10 días.

Corresponde insistir en esta parte que, en el control previo y facultativo, por razón de la representación del Contralor General de la República, el Tribunal Constitucional ejerce su atribución tanto por contravención directa o indirecta a la Constitución.

\subsection{Por el Tribunal Constitucional}

El Tribunal Constitucional ejerce un control previo o represivo y siempre facultativo de constitucionalidad de los decretos con fuerza de ley. Esto de conformidad con el artículo 93 No 4.

El 93 No $4^{\circ}$ señala: "Resolver las cuestiones que se susciten sobre la constitucionalidad de un decreto con fuerza de ley".

Luego, el mismo artículo 93 señala: "En el caso del número 40, la cuestión podrá ser planteada por el Presidente de la República dentro del plazo de diez días cuando la Contraloría

${ }^{9}$ Henríquez Viñas, Miriam (2009). Las fuentes formales del Derecho. Santiago: LegalPublishing, p. 84. 
rechace por inconstitucional un decreto con fuerza de ley. También podrá ser promovida por cualquiera de las Cámaras o por una cuarta parte de sus miembros en ejercicio en caso de que la Contraloría hubiere tomado razón de un decreto con fuerza de ley que se impugne de inconstitucional. Este requerimiento deberá efectuarse dentro del plazo de treinta días, contado desde la publicación del respectivo decreto con fuerza de ley".

De la lectura de la Constitución, puede concluirse que el Tribunal Constitucional está facultado para ejercer un control previo y abstracto de constitucionalidad cuando el decreto con fuerza de ley haya sido representado por la Contraloría General de la República, porque contraviene o excede la ley delegatoria o porque es contrario a la Constitución. En este supuesto, el legitimado activo es el Presidente de la República y el plazo que tiene para plantear el requerimiento es de 10 días contados desde que se reciba en el Ministerio de origen el oficio de representación del Contralor. Con el requerimiento debe acompañarse el decreto con fuerza de ley impugnado y el oficio en que conste la representación del Contralor General de la República, esto último de conformidad con el artículo 73 de la Ley Orgánica del Tribunal Constitucional.

Además, el Tribunal Constitucional puede ejercer un control represivo y abstracto de constitucionalidad, a requerimiento de cualquiera de las Cámaras o de una cuarta parte de sus miembros en ejercicio, dentro de los 30 días posteriores a la vigencia del decreto con fuerza de ley. En cuyo caso deberá acompañarse al requerimiento la respectiva publicación en el Diario Oficial, según el artículo 73 antes citado.

Luego, la Ley Orgánica del Tribunal Constitucional, contempla en su artículo 74 tres causales de inadmisibilidad del requerimiento a propósito del control de constitucionalidad del decreto con fuerza de ley abstracto y represivo, señalando: "Procederá la inadmisibilidad en los siguientes casos: 3) cuando la cuestión promovida por una de las Cámara o una cuarta parte de sus miembros en ejercicio se funde en alegaciones de legalidad".

Surge entonces la duda si el Tribunal Constitucional es competente para ejercer el control de constitucionalidad cuando el decreto con fuerza de ley excede o contraviene la ley delegatoria.

Sobre el particular, podrían proponerse al menos dos interpretaciones a la expresión "alegaciones de legalidad”. La primera, que la Ley Orgánica del Tribunal Constitucional sólo reiteró que el parámetro del control de constitucionalidad es la Constitución y que no puede serlo la ley. En cuyo supuesto, se mantendría la duda sobre si la conformidad a la Constitución lo es a ella directamente e indirectamente. La segunda interpretación es que la ley estableció, con la expresión "alegaciones de legalidad", que el control represivo, abstracto y facultativo de los decretos con fuerza de ley sólo procede cuando aquél es contrario a la Constitución y no cuando excede o contraviene la ley delegatoria, por ser esta última un vicio de legalidad. 
El Tribunal Constitucional ha sostenido desde el año 2003 de forma invariable que está facultado para resolver sobre los requerimientos que se planteen cuando un decreto con fuerza de ley excede o contraviene la ley delegatoria ${ }^{10}$.

Así en sentencia del año 2003 expresó: "De esta manera, es esta Magistratura la que debe resolver, en virtud de lo dispuesto en el artículo 82, $N^{\circ} 3$, de la Constitución, si el decreto con fuerza de ley fue correctamente representado por la Contraloría por alguna de las dos causales señaladas en el referido artículo 88, a saber: exceder o contravenir la ley delegatoria o contravenir la Constitución. Si el Presidente de la República puede recurrir a este Tribunal Constitucional en el evento que la Contraloría represente un decreto con fuerza de ley por exceder o contravenir la ley delegatoria, no se divisa razón para negarle a alguna de las Cámaras, o a la cuarta parte de los senadores o diputados en ejercicio, la posibilidad de recurrir, por el mismo motivo, a esta Magistratura, según se desprende de una interpretación armónica y sistemática de la Carta Fundamental. Concluir lo contrario significaría consagrar una evidente desigualdad en relación con la situación de los diversos titulares activos que pueden solicitar la intervención de este Tribunal, lo cual no es admisible atribuir al Constituyente"11.

La misma conclusión fue reiterada el año 2009, de la siguiente forma: "Que para resolver el primer argumento en que se funda la cuestión previa planteada, este Tribunal tiene presente que en su sentencia recaída en los Roles Nos 392, 393 y 394 (acumulados) ya resolvió favorablemente su competencia para conocer de los decretos con fuerza de ley, cuando éstos exceden o contravienen la ley delegatoria o son inconstitucionales, sea a requerimiento del Presidente de la República, de alguna de las Cámaras o de la cuarta parte de los Senadores o Diputados en ejercicio, no obstante lo que resuelva la Contraloría General de la República de acuerdo al artículo 99 de la Carta Magna, fundado ello en la desigualdad que implicaría una interpretación diversa"12.

La afirmación del Tribunal Constitucional sobre su competencia para ejercer el control de constitucionalidad tanto a requerimiento del Presidente de la República, de alguna de las Cámaras o de la cuarta parte de los Senadores o Diputados en ejercicio, con base en la desigualdad que implicaría una interpretación diversa, podría complementarse con la conclusión propuesta en este trabajo. Esto es, el Tribunal Constitucional es competente por cuanto toda vulneración del decreto con fuerza de ley a su ley delegatoria se traduce en una violación de la Constitución, aunque indirectamente.

Declarada la inconstitucionalidad del decreto con fuerza de ley por esta vía, éste se entenderá derogado desde la publicación en el Diario Oficial de la sentencia que acoja el reclamo, la que no producirá efecto retroactivo.

\footnotetext{
${ }^{10}$ STC Roles No 392, 393 y 394, 11 de noviembre de 2003; y Rol No 1191, 19 de mayo de 2009.

11 STC Roles No 392, 393 y 394, 11 de noviembre de 2003.

${ }^{12}$ STC Rol No 1191, 19 de mayo de 2009.
} 
Finalmente, como el decreto con fuerza de ley es una norma con fuerza de ley y jerarquía legal, es decir es un precepto legal, también puede cuestionarse su constitucionalidad por la vía del recurso de inaplicabilidad por inconstitucionalidad y sólo en la medida que se cumplan los requisitos previstos en el artículo 93 No 6 de la Constitución y los propios de la Ley Orgánica del Tribunal Constitucional.

Esta última afirmación ha sido corroborada por el Tribunal Constitucional cuando ha dicho: "Que, a la luz de lo antes indicado, este Tribunal no visualiza un fundamento normativo o histórico-jurídico que permita sostener que no procede solicitar la inaplicabilidad de un precepto legal contemplado en un decreto con fuerza de ley, según el artículo 93, $N^{\circ} 6^{\circ}$, de la Constitución, sea por razones de fondo o de forma. Es más; por razones de certeza juridica y protección de los derechos fundamentales, aplicando las normas constitucionales en su justa medida, no puede sino sostenerse que este órgano jurisdiccional puede $y$ debe asumir un control de constitucionalidad de los decretos con fuerza de ley cuando se vulneran las normas sustantivas que fundamentan su dictación, de acuerdo al artículo 93, $N^{\circ} 6^{\circ}$, de la Constitución. Por lo demás, este Tribunal en diversas causas anteriores ha conocido vicios de forma de normas pertenecientes a otro tipo de legislación irregular, como es el caso de los Decretos Leyes, sin que se cuestionara su competencia al respecto, como son los fallos recaídos en el artículo 116 del Código Tributario"13.

Por su parte, autores como Eduardo Cordero, advierten que este tipo de control, represivo y concreto de constitucionalidad, supone un cuestionamiento de constitucionalidad de ambas normas: ley delegante y decreto con fuerza de ley, en la medida que esta última se verá afectada por el vicio del cual adolece la primera.

\section{Conclusión}

El presente trabajo pretendió establecer la competencia del Tribunal Constitucional para ejercer el control de constitucionalidad de los decretos con fuerza de ley cuando las Cámaras o una cuarta parte de sus miembros recurren al órgano de justicia constitucional para impugnarlo por exceder o contravenir la ley delegatoria. Para ello, fue necesario dilucidar si el supuesto expuesto es un vicio de legalidad o de constitucionalidad, lo que puede deducirse una vez desentrañada la relación del decreto con fuerza de ley con su ley delegatoria.

A mi juicio, existe una particular relación entre el decreto con fuerza de ley y su ley delegatoria. Esto, por cuanto la ley delegatoria es una ley de carácter especial en el sentido de que se dicta sólo para atribuir competencia al Presidente de la República para que pueda regular materia propia de ley mediante la dictación del decreto con fuerza de ley. De esta forma, la ley delegatoria proporciona la medida para comprobar si el decreto con fuerza de ley ha vulnerado la Constitución. Así, toda vulneración del decreto con fuerza de ley a su ley delegatoria se traduce en una violación de la Constitución, aunque indirectamente.

${ }^{13}$ STC Rol No 1191, 19 de mayo de 2009. 
Como consecuencia de lo anterior, el Tribunal Constitucional está facultado para conocer de la constitucionalidad de los decretos con fuerza de ley cuando éstos exceden o contravienen la ley delegatoria o son inconstitucionales, sea a requerimiento del Presidente de la República, de alguna de las Cámaras o de una cuarta parte de sus miembros en ejercicio. A esta conclusión también ha arribado el Tribunal Constitucional invariablemente desde el año 2003, fundado en la desigualdad que implicaría una interpretación diversa.

\section{BiBLIOGRAFÍA CITADA}

Cordero Quinzacara, Eduardo (2010). "La legislación delegada en el derecho chileno y su función constitucional”. Revista Estudios Constitucionales, Año 8, No 2, pp. 49-86.

GARCíA DE ENTERRÍA, Eduardo (1998). Legislación delegada, potestad reglamentaria y control judicial. Madrid: Editorial Civitas, 360 pp.

Gutiérrez Gutiérrez, Ignacio (1995). Los controles de la legislación delegada. Madrid: Centro de Estudios Constitucionales, $342 \mathrm{pp}$.

Henríquez Viñas, Miriam (2009). Las fuentes formales del Derecho. Santiago: LegalPublishing, 119 pp.

Henríquez Viñas, Miriam (2010). "El control de constitucionalidad de los decretos con fuerza de ley en la Ley Orgánica del Tribunal Constitucional”. En: Temas de Derecho Procesal Constitucional. Reflexiones juridicas sobre competencias del Tribunal Constitucional y la nueva LOC del Tribunal Constitucional, NogUeIRA Alcalá, Humberto (Coord.), Santiago: Librotecnia, pp. 147-160.

Molina Guaita, Hernán (2001). "Los decretos con fuerza de ley en la Constitución". Revista de Derecho Universidad Católica de Valparaiso, XXII, pp. 421435.

Nogueira Alcalá, Humberto (2001). "La delegación de facultades legislativas en el ordenamiento jurídico chileno”. Revista Ius et Praxis, Año 7, No 2, pp. 7385.

Ribera Neumann, Teodoro (2004). "El control de constitucionalidad de los decretos con fuerza de ley por el Tribunal Constitucional". Revista de Derecho Público, No 66, pp. 121-144.

ZúNiga Urbina, Francisco (2002). Elementos de Jurisdicción Constitucional. T. II, Santiago: Ediciones Universidad Central.

\section{JURISPRUDENCIA CITADA}

Tribunal Constitucional, Roles No 392, 393 y 394, 11 de noviembre de 2003 (requerimiento de inconstitucionalidad respecto del decreto con fuerza de ley No 21, de 2003, del Ministerio de Hacienda, publicado en el Diario Oficial de fecha 13 de septiembre de 2003). 
Tribunal Constitucional, Rol No 1191, 19 de mayo de 2009 (requerimiento de inaplicabilidad en relación con la aplicación del artículo 137 del DFL No 1, de 22 de junio de 1982, del Ministerio de Minería, Ley General de Servicios Eléctricos). 